Article

\title{
Impact of Microplastic Fibers from the Degradation of Nonwoven Synthetic Textiles to the Magdalena River Water Column and River Sediments by the City of Neiva, Huila (Colombia)
}

\author{
Paula Martínez Silva ${ }^{1}\left(\mathbb{D}\right.$ and Mark A. Nanny ${ }^{2, *}$ \\ 1 Environmental Engineering Department, Corhuila University, Neiva 410005, Colombia; \\ paula.martinez@corhuila.edu.co \\ 2 School of Civil Engineering and Environmental Science, Gallogly College of Engineering, and Institute for \\ Energy and the Environment, Mewbourne College of Earth and Energy, University of Oklahoma, Norman, \\ OK 73019, USA \\ * Correspondence: nanny@ou.edu
}

Received: 30 March 2020; Accepted: 16 April 2020; Published: 24 April 2020

check for updates

\begin{abstract}
Magdalena River surface water and shoreline sediments were sampled for microplastic particles at three locations in the city of Neiva, Colombia: upstream, city center, and downstream of the raw wastewater outflow. The absence of an industrial and manufacturing sector in Neiva provided an opportunity to assess the impact of upstream agricultural practices, as well as municipal activities such as wastewater outflow and laundry washing, on the quantity, polymer composition, and morphology of microplastic particles produced per capita and entering a river system. Microplastic particle concentrations increased with downstream distance, with microfiber concentrations ranging from 0.097 to 0.135 fibers $/ \mathrm{L}$ in the river water and 25.5 to 102.4 fibers $/ \mathrm{kg}$ in shoreline sediment. Microplastic fragment concentrations were $0.013-0.028$ fragments $/ \mathrm{L}$ in surface water and 10.4-12.7 fragments $/ \mathrm{kg}$ of sediment. Raman microscope and scanning electron microscopy identified the relative composition of the polymers comprising the microplastic particles was similar regardless of sampling site or whether the sample was collected from the surface water or shoreline sediments, with polypropylene and polyethylene comprising at least $75 \%$ of the total polymers in all samples. Average fiber widths of $<20 \mu \mathrm{m}$ in all but one sample, along with the lack of acrylic and polyester fibers used predominantly in woven synthetic textiles, indicated that the degradation of nonwoven synthetic textiles is the predominant origin of these microplastic fibers in the Magdalena River.
\end{abstract}

Keywords: microplastics; water column; sediments; nonwoven fibers

\section{Introduction}

Microplastics are plastic particles with a diameter less than $5 \mathrm{~mm}$ and are categorized into two classes according to their origin: primary or secondary. Primary microplastics are those specifically manufactured at a microscale size for use in cosmetics, exfoliating scrubs, and dental paste, while secondary microplastics are those that form through degradation of plastic materials and synthetic textiles [1-3]. Depending on the research focus, microplastics are also categorized according to their size, shape, color, and polymeric composition [4]. Environmental inputs of microplastic particles include release of treated or raw sewage [2], degradation of plastic debris and packaging, particle runoff from roads, and most recently discovered, wind transport [5-7]. Microplastics are of special concern given their small size, their potential for environmental dispersal, their impacts on biota, and their ability to absorb hydrophobic pollutants [8,9]. While initial microplastic particle research focused on 
characterizing contamination of marine environments e.g., [10], later research demonstrated that most plastic debris found in the oceans originated from large populated areas with rivers being one of the most important transport mechanisms for microplastic particles to the ocean [11-15]. Despite the importance of river transport of microplastic particles, the comprehensive studies of microplastic particle origins, concentrations, and fate in river water and sediments is still in its early stage. Over the past two years, studies of global river systems have shown that microplastic particle concentrations range from $10^{-1}$ to $10^{3}$ particles/L in water columns and 10 to $10^{5}$ particles $/ \mathrm{kg}$ in sediments [16-36] regardless of population density, land use (i.e., agriculture, industrial, municipal, rural), climatology, hydrology, or geography. The lack of clear, consistent correlations between microplastic particle behavior and environmental parameters challenges efforts to mitigate and control microplastic pollution in surface waters and the open oceans.

The objective of this study was to sample the reach of the Magdalena River that flows through Neiva, Colombia to measure the microplastic concentrations in the river water and sediments and characterize the origins of these particles. Neiva is a metropolis of nearly 336,000 people and located on the Magdalena River high basin in the southern Colombian Andes. Neiva does not have industrial or manufacturing sectors, acting mostly as a commerce and distribution center for agricultural products produced in the surrounding rural areas, notably upstream of Neiva. Thus, Neiva represents a modestly sized urban sampling site that is predominantly impacted by microplastic particle inputs from wastewater, laundry washing, surface runoff, and upstream agricultural practices. By comparing upstream and downstream water and sediment microplastic concentrations, morphology and polymer compositions, an estimation of the amount and type of microplastic particles produced per capita can be developed. These findings will provide an understanding of the type of microplastic particle pollution produced by people without interferences from microplastic particles produced by industry and manufacturing.

\section{Materials and Methods}

\subsection{Sampling}

Sampling was done along the Magdalena River in Neiva, Colombia. Neiva is located in the valley between the Cordillera Central and Cordillera Oriental mountains at an elevation of $442 \mathrm{~m}$. The headwaters of the Magdalena River are at an elevation of $3800 \mathrm{~m}$ and located $263 \mathrm{~km}$ south of Neiva. Figure 1 provides a map of the three sampling sites selected along the Magdalena River in the city of Neiva, Colombia. The southernmost site (Site 1) was upstream of Neiva, located at $2^{\circ} 91^{\prime} 54^{\prime \prime} \mathrm{N}$ and $75^{\circ} 29^{\prime} 04^{\prime \prime} \mathrm{W}$ between Neiva and the Betania hydroelectric reservoir. The second site (Site 2) was at the main fish market in central Neiva located at $2^{\circ} 92^{\prime} 91^{\prime \prime} \mathrm{N}$ and $75^{\circ} 29^{\prime \prime} 74^{\prime \prime} \mathrm{W}$ and the third site (Site 3) was immediately downstream of the raw municipal waste water and sewage water discharge located at $2^{\circ} 94^{\prime} 56^{\prime \prime} \mathrm{N}$ and $75^{\circ} 30^{\prime} 93^{\prime \prime}$ W. Sampling occurred during August 18-20, 2018. Surface water samples were collected using a Neuston net of $20 \mu \mathrm{m}$ mesh size, filtering the surface water to the depth of the neuston net mouth $(0.3 \mathrm{~m})$ for $30 \mathrm{~min}$ at a speed of 2 knots [33,37-40] so that the sampled water volume was $\approx 1 \mathrm{~m}^{3}$ [41,42]. Sediment samples were collected on the shore along a horizontal transect at the waterline [37-39,42,43] by obtaining approximately $1 \mathrm{~kg}$ of sediment using a metal shovel to a depth of $5 \mathrm{~cm}$. Three sediment sample replicates $(1 \mathrm{~kg}$ each) were collected and combined into a single sample for each site [9]. Sediment and water samples were transported in glass containers to the laboratory. 


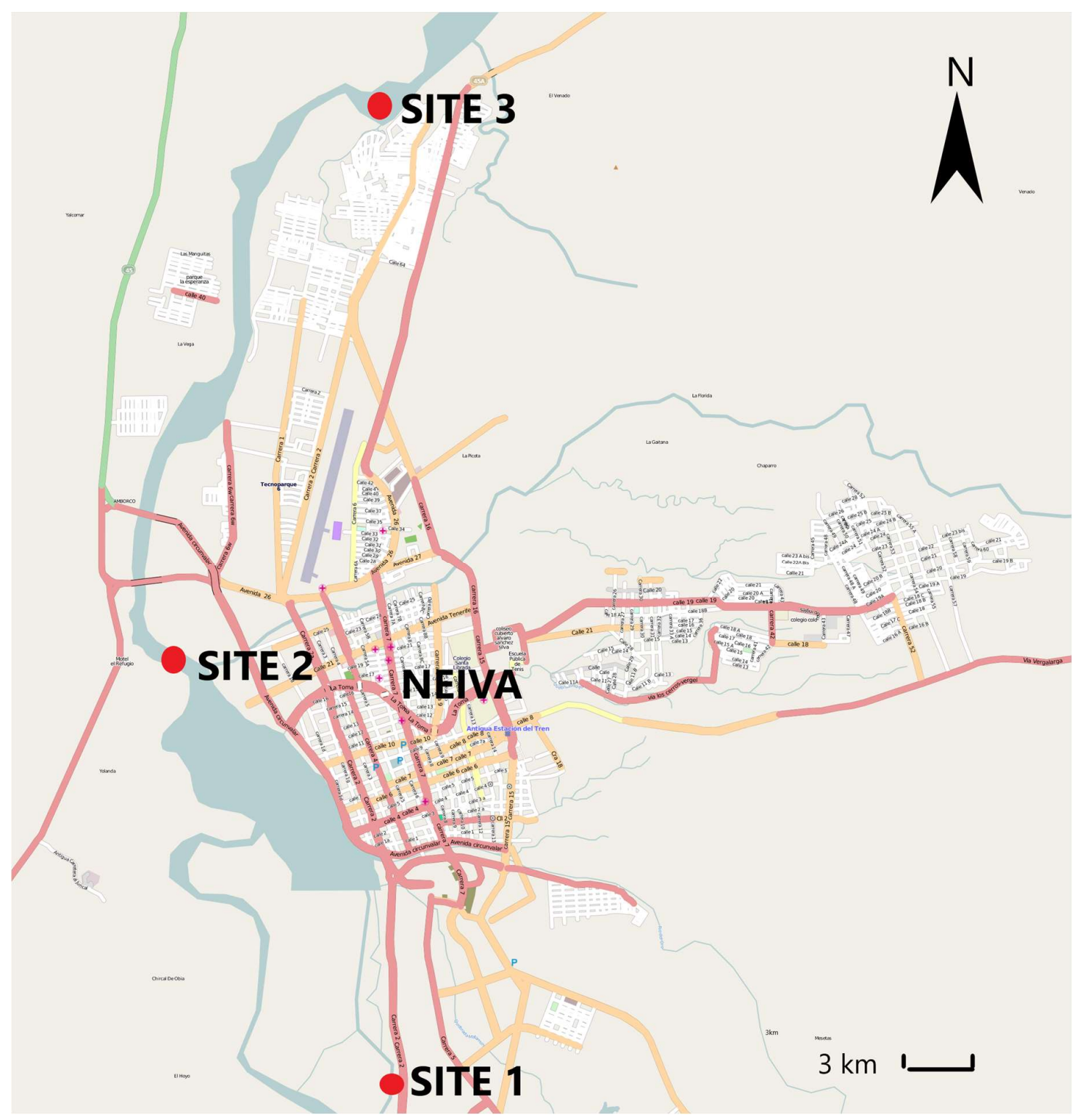

Figure 1. Map showing sampling sites in Neiva, Colombia, along the Magdalena River.

\subsection{Microplastic Particle Isolation}

Sediment samples were air dried and sieved with a $2 \mathrm{~mm}$ metallic mesh. Microplastic particles were isolated from sediment and water samples using a saturated sodium chloride solution $\left(1.202 \mathrm{~g} / \mathrm{cm}^{3}\right)[44,45]$. This procedure was repeated three times to remove low density microplastic particles [46]. Isolated sediment samples and water samples were filtered with $0.45 \mu \mathrm{m}$ pore glass fiber Whatman filters [44-47]. To avoid loss of microplastic particles due to adherence, the walls of the glassware were rinsed repeatedly during the filtration process [43]. The efficiency of the sodium chloride density separation was evaluated using an aqueous solution with known concentrations of polystyrene (PS), polyethylene (PE), polypropylene (PP), polyvinyl chloride (PVC), and polyethylene terephthalates (PET) microplastic particles. Microplastic particles were produced by filing plastic samples of known polymer composition. The recovery of each individual polymer was measured by producing a $250 \mathrm{~mL}$ test solution with 50 particles. After three extractions, the efficiency for low density microplastics was $93 \%$ (PS, PE and PP) and the efficiency for high density microplastics (PVC and PET) was $79 \%$. 


\subsection{Microplastic Particle Characterization}

Optical microscopy (Olympus CX33, Bogota, Colombia, 100X magnification) was used to quantify the number of pellets, fragments, and fibers collected on the filters. Microplastic particle shapes were classified as pellets (spherical primary microplastics), fragments (irregular shapes presumably derived from the physical degradation of larger plastic debris), and fibers (from fishing lines, nets, clothing, and non-woven textiles) [48,49]. A Renishaw confocal Raman microscope (inVia Qontor, Renshaw, West Dundee, IL, USA) was used to characterize the microplastic particle polymer composition. Microplastic particles were characterized using $20 \times$ and $50 \times$ objectives with a $532 \mathrm{~nm}$ laser and 1200 scanning counts. Laser intensity, exposure time, and number of integrations were set individually for each particle or fiber depending on the background fluorescence observed [50,51]. Calibration used the $520.7 \mathrm{~cm}^{-1}$ peak of a pure silicon wafer and the spectrum of a clean filter was subtracted from sample analyses. Raman spectra of polymers (PP, PE, PS, PVC, and Nylon) collected from consumer materials and Raman spectra from the literature were used as a reference data base for polymer identification [52-58].

Scanning electron microscopy (SEM) was used to obtain high resolution images of the samples and to improve particle counting, considering that microplastics can be distinguished from other organic or inorganic materials by examining the high-resolution images of their surface morphology [37-39]. Samples were rinsed with nanopure water for several minutes and filtered again with glass fiber filters. Samples on the glass fiber filters were air-dried for $24 \mathrm{~h}$ and gold-sputter coated in a Hummer VI sputtering system. Micrographs were collected on a Zeiss Neon 40 EsB Scanning Electron Microscope (Oberkochen, Germany) with an accelerating voltage of $2.0 \mathrm{kV}$ and a secondary electron detector. The entire filter area was analyzed completely $\left(5 \mathrm{~cm}^{2}\right.$ per filter), collecting images of $0.5 \mathrm{~cm}^{2}$ and greater magnified images where microplastics were found $\left(1 \mathrm{~mm}^{2}\right)$ in order to have a better image for the analysis. The images obtained were used to obtain the particle size distribution [49]. The surface area of microplastic particles and microspheres as well as the length and width of microfibers were measured using Image $[58,59]$, a free distribution software for image analysis. Particle area and fiber length and width data were processed using the software SPSS, applying a Kruskal-Wallis test with a level of confidence of $95.5 \%$ to identify any significant difference in the quantity of microplastics and their geometry among sampling sites $[36,59,60]$.

\section{Results}

Figure 2 illustrates that at all three sampling sites, fibers constituted the majority of microplastic particles found in both the river surface water and the shoreline sediments, followed by fragments, and a small number of pellets present only in the shoreline sediment samples. Totally, 999 microplastic particles were characterized from all three sites combined, with $84 \%$ identified as fibers, $15 \%$ as fragments, and $1 \%$ as pellets. Additionally, the concentration of fibers and fragments in the river surface water (\# particles/L) and the shoreline sediments (\# particles/kg) increased with downstream distance. 


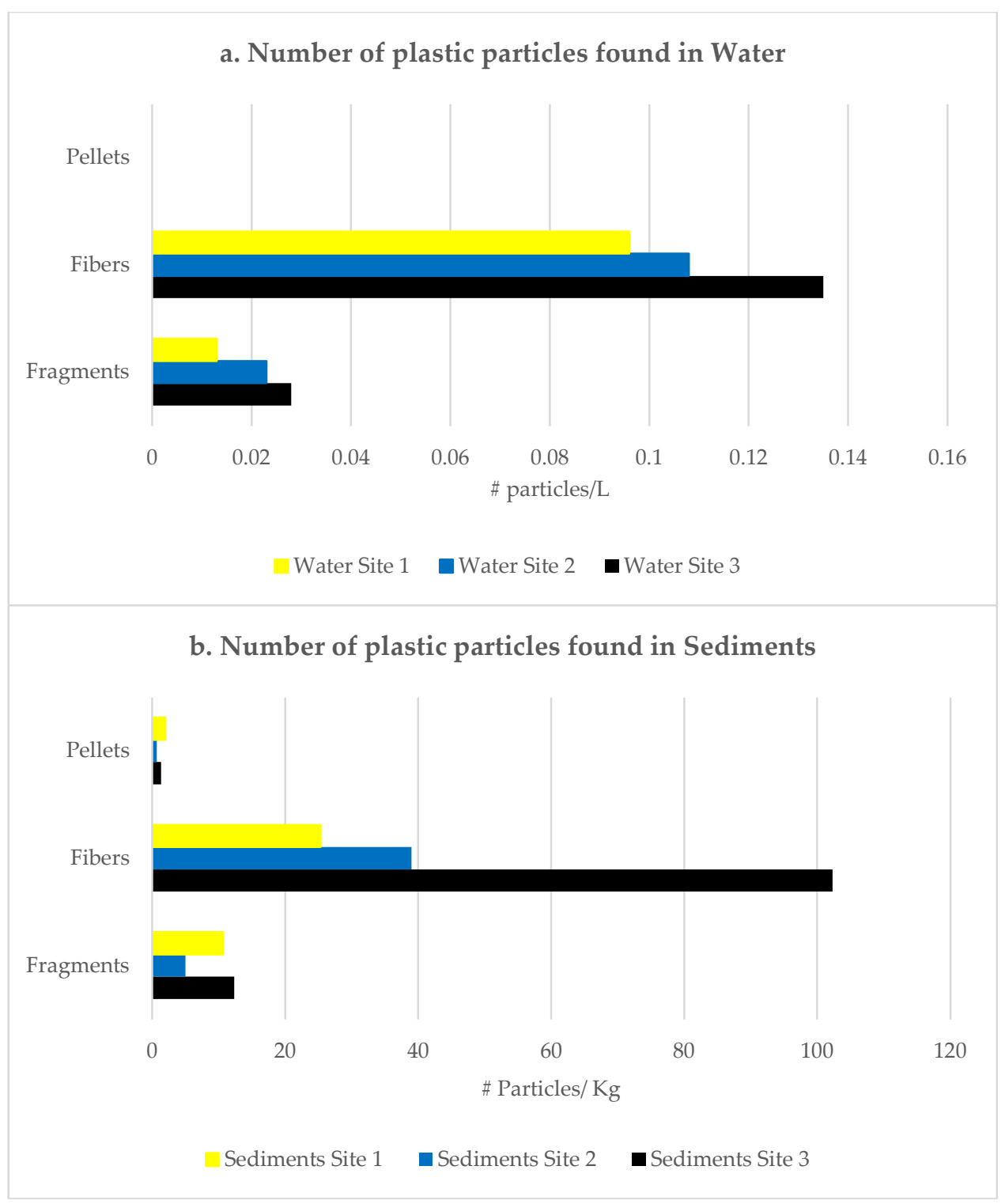

Figure 2. Number of microplastic particles (Graphic a. Shows \# particles/L, Graphic b. Shows \# particles/kg for sediments) found in each site according to their shape.

Figure 3 shows that the relative composition of the polymers comprising the microplastic particles was very similar regardless of sampling site or whether the sample was collected from the surface water or shoreline sediments. In all samples, the fiber composition consisted of $\approx 50 \%$ polypropylene $(\mathrm{PP}), \approx 33 \%$ polyethylene $(\mathrm{PE}), \approx 10 \%$ nylon, and $\approx 5 \%$ polystyrene (PS). Blank tests with laboratory distilled water demonstrated Neuston net fibers (comprised of PP and PET) were not contaminating the surface water samples. With regards to microplastic fragments, their composition consisted of $\approx 50-60 \%$ polyethylene terephthalate $(\mathrm{PET}), \approx 25-30 \% \mathrm{PP}$, and $\approx 10-20 \% \mathrm{PE}$. The pellet composition in all three sediment samples was $100 \%$ PE. 


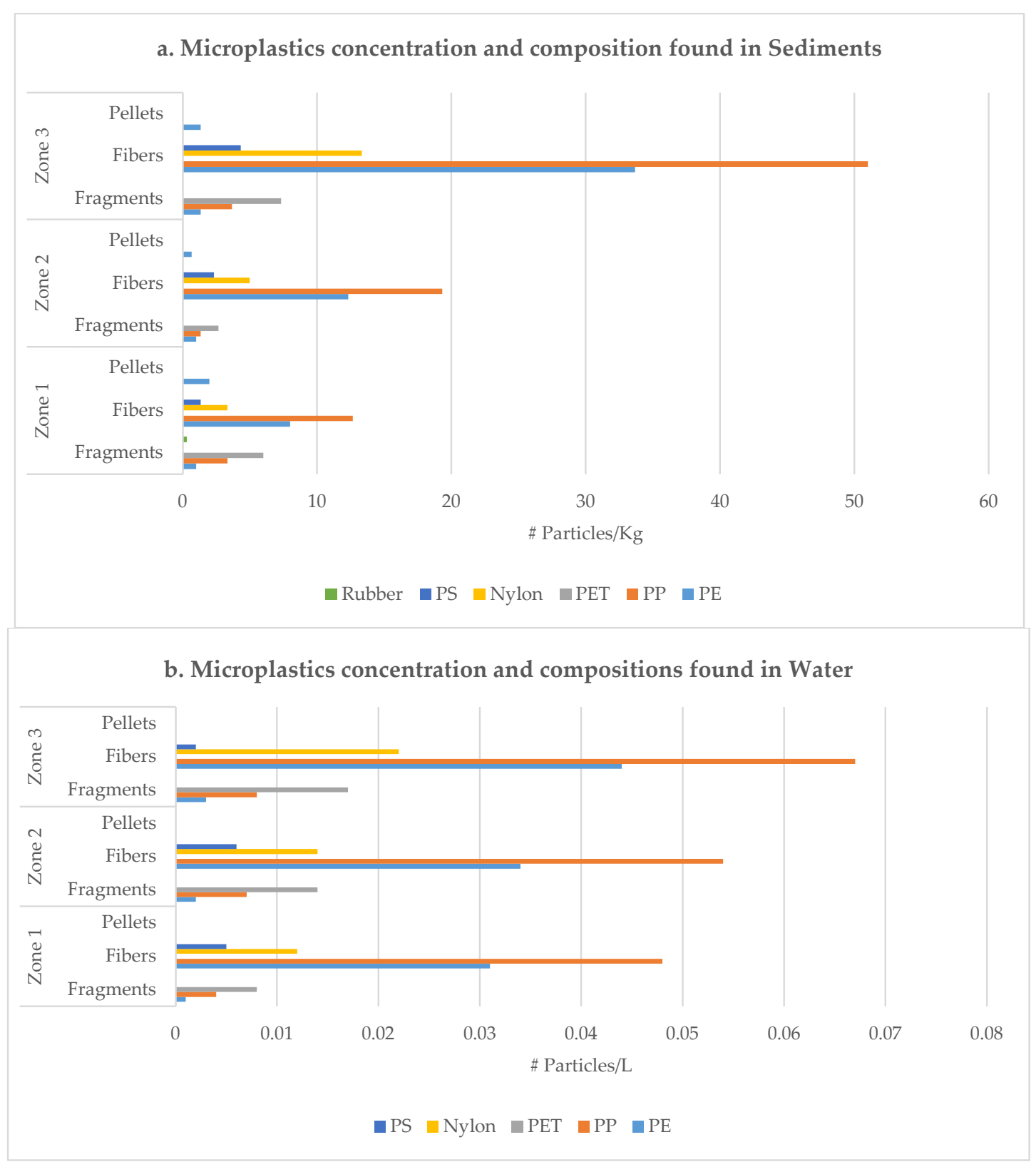

Figure 3. Microplastic concentrations and compositions found in shoreline sediments and surface water for each site. Polystyrene (PS), polyethylene terephthalate (PET), polypropylene (PP), polyethylene (PE). Graphic a shows the results for sediments, graphic $b$ shows the results for water.

Figure 4 presents the range of particle areas $\left(\mu \mathrm{m}^{2}\right)$ for the fragments and pellets found in each sample. The average area for particles in the water samples ranged from 3.03 to $9.22 \mu \mathrm{m}^{2}$, and for particles in the sediment samples, it ranged from 2.55 to $17.96 \mu \mathrm{m}^{2}$. There is no statistical difference in the average particle areas of fragments and pellets among the six samples (with a significance of $p=0.05$ ). However, the shoreline sediments at sampling site 3 (SS3) contained the greatest variation of particle areas, as well as several fragments with uniquely large areas. 


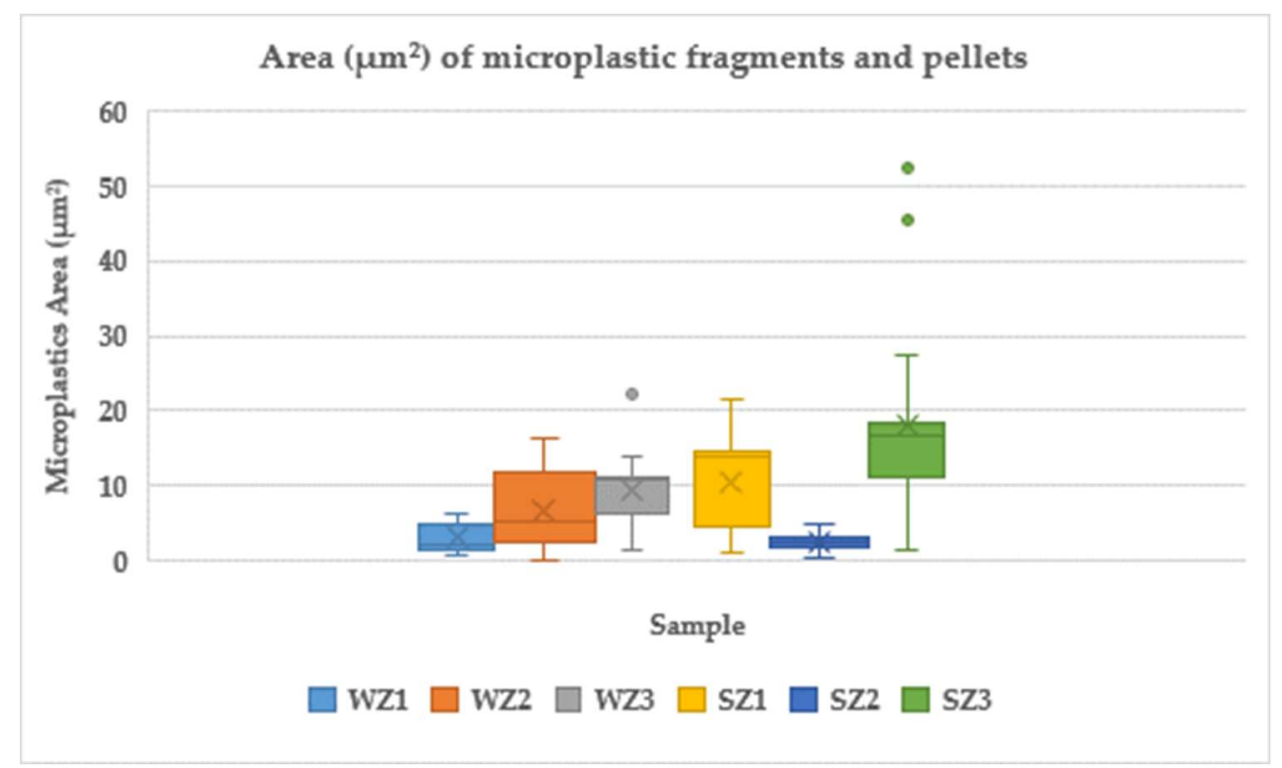

Figure 4. Area $\left(\mu \mathrm{m}^{2}\right)$ of microplastic fragments and pellets found in all six samples. Box plots depict range of particle areas with top whisker equal to the 90th percentile of areas, top of the box equal to the 75th percentile, bar at middle of box equal to the 50th percentile, bottom of box equal to the 25th percentile, and bottom whisker equal to the 10th percentile. Dots above the top of the whisker represent large area values that occur outside the quartiles represented, showing that the biggest fragments occur at Site 3. The number of microplastic particles in each sample are Water Site 1 (WZ1: nine fragments), Water Site 2 (WZ2: 17 fragments), Water Site 3 (WZ3: 23 fragments), Sediment Site 1 (SZ1: 22 fragments, four pellets), Sediment Site 2 (SZ2: 10 fragments, zero pellets), and Sediment Site 3 (SZ3: 19 fragments, three pellets). The $X$ inside the boxes represents the average data (WZ1: $3.03 \mu \mathrm{m}^{2}$, WZ2: $6.45 \mu \mathrm{m}^{2}$, WZ3: $9.22 \mu \mathrm{m}^{2}$, SZ1: $10.29 \mu \mathrm{m}^{2}$, SZ2: $2.55 \mu \mathrm{m}^{2}$, SZ3: $17.96 \mu \mathrm{m}^{2}$ ).

Figure 5 shows the range of width $(\mu \mathrm{m})$ and length $(\mu \mathrm{m})$ for fibers found in each sample. The average width and length for microplastic fibers in water samples ranged from 10 to $14 \mu \mathrm{m}$ and 300 to $400 \mu \mathrm{m}$, respectively. For sediment samples, the average width and length of microplastic fibers ranged from 14 to $24 \mu \mathrm{m}$ and 300 to $600 \mu \mathrm{m}$, respectively. Using the Kruskal-Wallis test, at the level of 0.05 of significance, all six samples are different with the probability of them being identical in composition much lower than $0.01 \%$ in both cases $\left(4.28 \times 10^{-28}\right.$ for width and $9.58 \times 10^{-10}$ for length). Figure 5 also shows for all six samples that the fiber width and length distributions are asymmetrical, given that the middle bar of the boxes is not in the middle of all four quartiles. Most samples have values outside the quartiles showing wide variability of fiber sizes, especially sediments from Site 3, that exhibits the highest average and the highest variation of values. 
a. Width of Microplastic fibers in $\mu \mathrm{m}$ found in all six samples

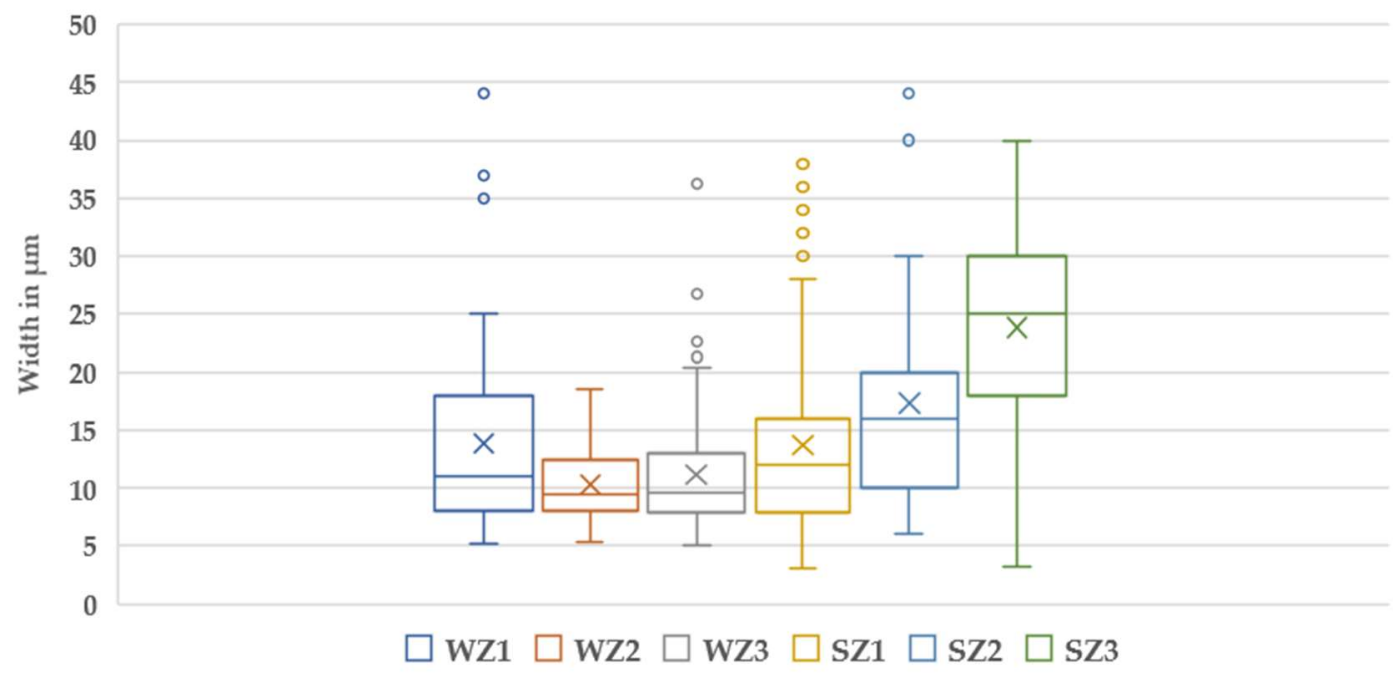

b. Length of microplastic fibers in $\mathrm{mm}$ found in all six samples

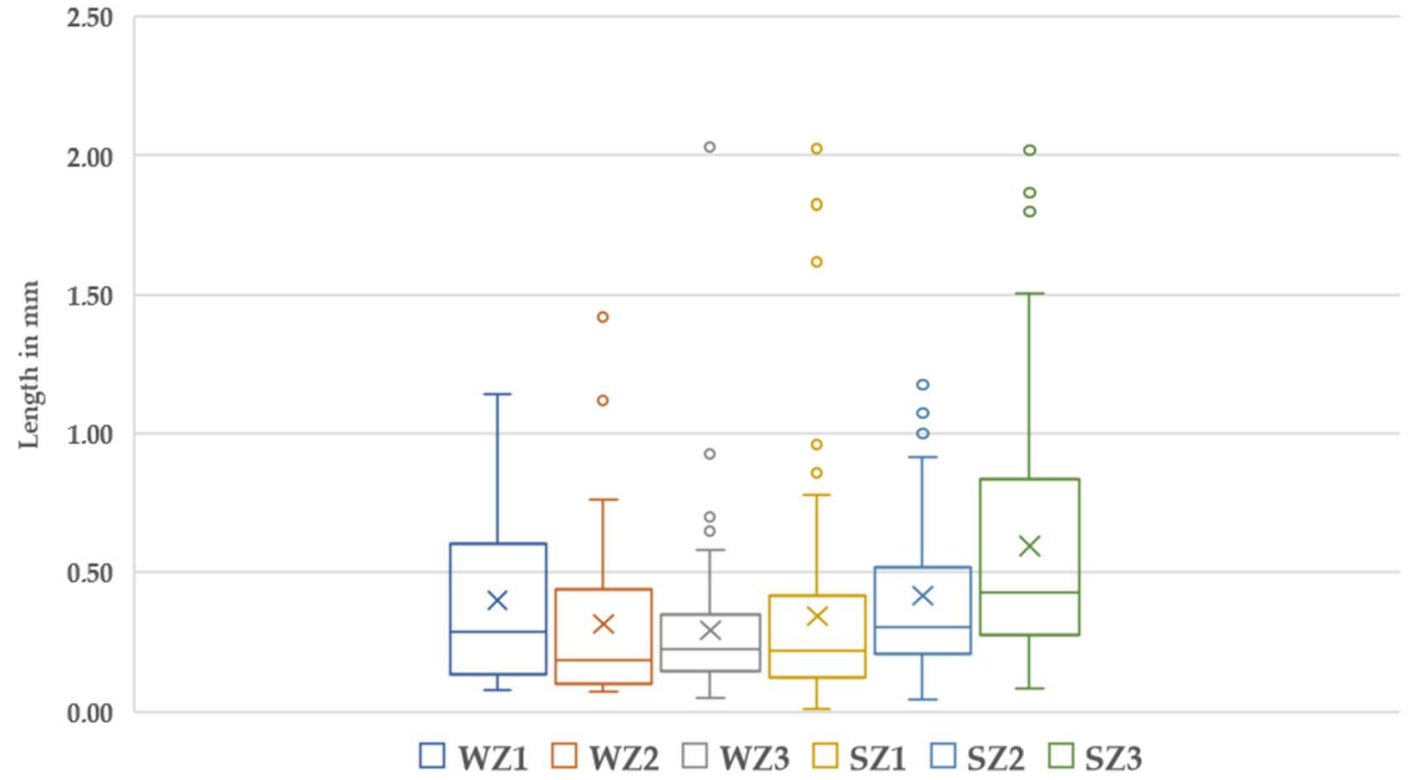

Figure 5. Width and length of microplastic fibers in $\mu \mathrm{m}$ found in all six samples. Box plots depict range of width or length with top whisker equal to the 90th percentile, top of the box equal to the 75th percentile, bar at middle of box equal to the 50th percentile, bottom of box equal to the 25th percentile, and bottom whisker equal to the 10th percentile. Dots above the top of the whisker represent large width or length values that occur outside the quartiles represented, in which we can see fibers up to 45 $\mu \mathrm{m}$ of width and up to $2000 \mu \mathrm{m}$ long. The number of microplastic fibers in each sample are Water Site 1 (WZ1: 53), Water Site 2 (WZ2: 31), Water Site 3 (WZ3: 72), Sediment Site 1 (SZ1: 82), Sediment Site 2 (SZ2: 36), and Sediment Site 3 (SZ3: 114). The $X$ inside the boxes shows the average data for width (WZ1 $14 \mu \mathrm{m}, \mathrm{WZ2} 10 \mu \mathrm{m}, \mathrm{WZ3} 11 \mu \mathrm{m}, \mathrm{SS} 114 \mu \mathrm{m}, \mathrm{SZ2} 17 \mu \mathrm{m}, \mathrm{SS3} 24 \mu \mathrm{m}$ ) and length (WZ1 $400 \mu \mathrm{m}$, WZ2 $300 \mu \mathrm{m}, \mathrm{WZ3} 300 \mu \mathrm{m}, \mathrm{SS} 1300 \mu \mathrm{m}, \mathrm{SZ2} 400 \mu \mathrm{m}, \mathrm{SZ3} 600 \mu \mathrm{m})$. Graphic a shows the width of fibers, Graphic b shows the length of fibers.

\section{Discussion}

Neiva, Colombia represents a unique sampling site to address the questions of what type of microplastic particles and how many microplastic particles are produced per person in an 
urban environment absent of heavy industrial and manufacturing processes. Neiva is the capital of the Department of Huila that has an economy consisting primarily of agriculture, livestock, and aquaculture [61]. The Magdalena River watershed upstream of Neiva consists of numerous small towns with diverse agricultural economies. The assumption made in this study is that microplastic particles produced during machining, grinding, milling, and fabrication processes associated with heavy industry are significantly different from microplastic particles generated by an urban populace using synthetic woven and nonwoven fabrics, plastic packaging and containers, and plastic consumer goods.

Figure 2 illustrates an increasing concentration of microplastic particles in water and sediment samples as a function of downstream distance, and by inference, increasing population. What is remarkable about these results are the similarities for the relative amounts of fragments, fibers and pellets (Figure 2) and for the relative concentrations of the polymer compositions for fragments, fibers, and pellets (Figure 3) in water and sediment samples regardless of sampling site location. These results suggest similar origins for microplastic particles whether they are produced in the upstream, rural area or in the urban, highly populous area. They also indicate the absence of preferential deposition of microplastic morphology and/or polymer composition over the sampled reach of the Magdalena River. It is hypothesized that the lower concentration of microplastic particles in sediment \#2 is because its texture is a dense clay that does not entrap particles efficiently while the texture of sediments \#1 and \#3 is sandy and can easily collect large particles.

In the region upstream of urban Neiva, microplastic particle inputs can originate from agricultural practices and the release of raw sewage and laundry wash water. Agricultural practices generating microplastic particles are the use of sludge-based fertilizers [62,63] and plastic mulches [63-67]. These agricultural practices produce microplastic particles that are predominantly black-colored and transparent fragments and films comprised mostly of polypropylene and polyethylene, along with a lesser amount of fibers $[68,69]$. Raw sewage contains microplastic particles with diverse morphology and polymer composition, however for many raw sewage influents, microplastic fibers typically comprise between $60 \%$ and $90 \%$ of the total microplastic particles [70-76]. Moreover, these fibers are typically comprised of acrylic, polyester, or polyamide polymers, presumably originating from washing clothing made of woven synthetic textiles [77-80].

Microplastic fragments comprised of PET, PP, and PE were identified in the water and sediment samples collected at all three sampling sites (Figure 3). A rubber fragment found in the sediment at Site 1 presumably originates from tire degradation [81,82]. PET, PP, and PE polymers are widely used for consumer packaging, grocery bags, food containers and drinking water bottles, so the hypothesized origin of these fragments is the mechanical degradation of these polymeric materials after their disposal. Moreover, in Site 1, the physical degradation of plastic mulches and crop covers used for agriculture upstream of Neiva could contribute to the microplastic fragment content. The microplastic fragments found in Site 3 illustrates preferential deposition of larger fragments presumably influenced by sewage outflow.

The microplastic fibers identified in water and sediment samples from all three sites contained similar relative compositions of PP, PE, Nylon, and PS (Figure 3). The absence of acrylic and polyester fibers used in woven synthetic textiles suggests a minimal contribution of microplastic fibers from laundry wash water [78-80]. This is a surprising finding for Site 3 considering it is not far downstream of raw sewage outflow. Figure 5 shows that the average width of these fibers for the water samples ranges between 10 and $14 \mu \mathrm{m}$, and for the sediment samples ranges from 14 to $24 \mu \mathrm{m}$, which is a width thinner than fibers typically used for woven synthetic textiles such as $17.2-44 \mu \mathrm{m}$ for PE, 18-50 $\mu \mathrm{m}$ for PP, and 18.8-26.6 for Nylon 6.6 [83-85]. Both the polymer composition and the thin fiber width indicate that these fibers originate from degradation of nonwoven textiles. Nonwoven textiles are a rapidly growing global market with sales of $\$ 44.37$ billion in 2017 to an estimated sales amount of $\$ 98.78$ billion by 2026 [86]. These textiles can be designed to offer precise functions such as absorbency, straining, resilience, stretch, strength, flame retardancy, wash ability, softness, bacterial barrier, and sterility [87-90]. Nonwoven textiles are used in a wide range of disposable products 
including healthcare products, filters, cleaning and medical wipes, personal hygiene products, diapers and absorbent pads, and water-resistant packaging, as well as bags, tarps, and textiles for clothing and upholstery [87]. Nonwoven textiles are a fabric organized from long polymer fibers, bonded collectively by mechanical, thermal, or solvent treatment to produce smooth, porous, and highly durable sheets consisting of thin fibers with widths ranging from 10 to $17 \mu \mathrm{m}$ [90]. Figure 6D shows an image of microplastic particle, found in a sediment sample, of a nonwoven textile consisting of an aggregated cluster of 10-15 $\mu \mathrm{m}$ wide fibers. Typical polymers used for nonwoven textiles are PE, PP, PS, and Nylon although other polymers are utilized [90]. Moving downstream from Site 1 to Site 3 , Figure 3 shows that these fibers accumulate in the sediments. Additionally, Figure 5 shows that moving downstream, the average width of the fibers increases, indicating additional contributions of thicker fibers used in woven textiles. The average fiber length found in the water and sediment samples from all three sampling sites was between 300 and $600 \mu \mathrm{m}$ (Figure 5).

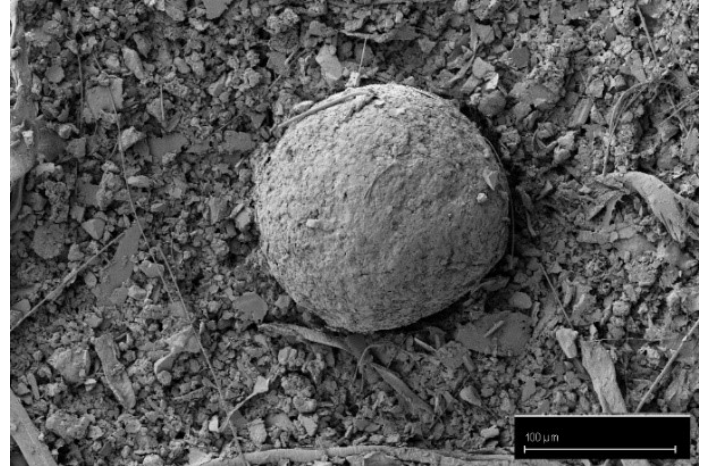

(a)

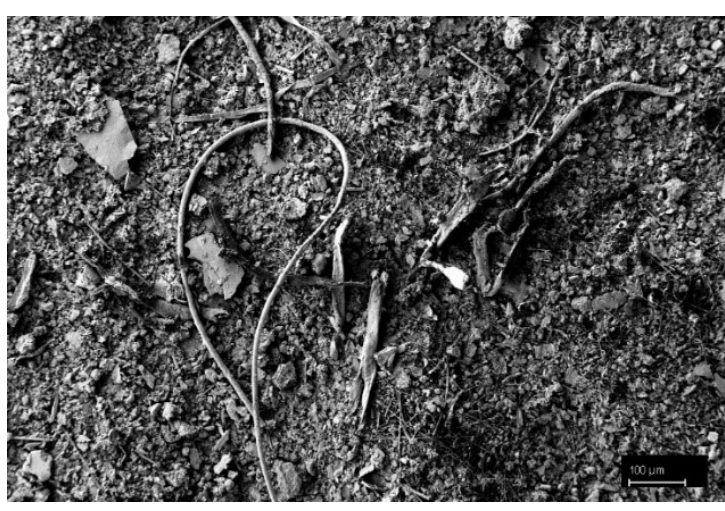

(c)

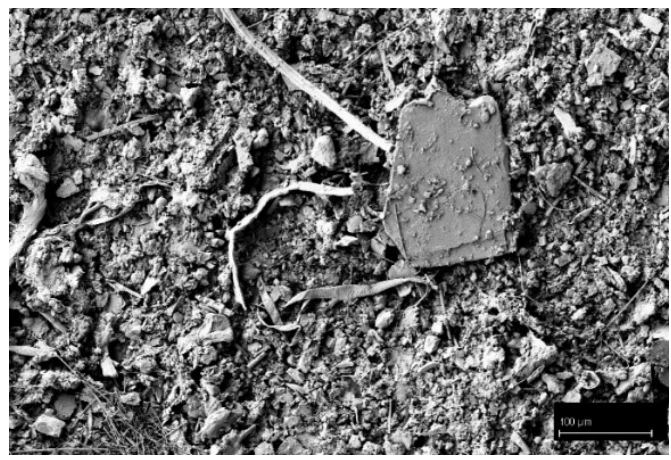

(b)

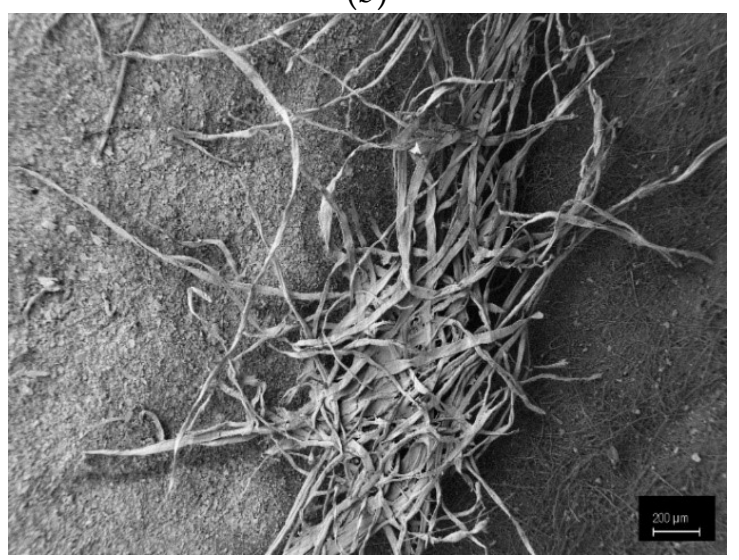

(d)

Figure 6. Micrography of the microplastics found. (a) Microsphere; (b) PET fragment; (c) fiber from clothing; (d) nonwoven fiber from packaging materials.

Since all water samples were collected within a two-day period during which the Magdalena River maintained a constant hydrological flow (i.e., no hydrological events such as rainfall), and assuming the concentration of microplastic particles in the surface water is representative of the average annual surface water concentration, the estimated average annual outflow of microplastic fibers and fragments per person can be calculated. Neiva's population in the urban region (urban area $=45.94 \mathrm{~km}^{2}$ ) directly adjacent to the three sampling sites in this study is 335,994 [91] resulting in an urban population density of 7317 people $/ \mathrm{km}^{2}$. Defining the amount of microplastic particles outflow produced per person by Neiva's urban population as the difference in microplastic particles collected between the water surface upstream and downstream sampling sites (Figure 2; Sites 1 and 3, respectively) giving values of 0.038 fibers/L and 0.015 fragments/L, and an average flow rate for the Magdalena River of $300 \mathrm{~m}^{3} / \mathrm{s}$ [92], it is 
calculated that Neiva's annual per capita outflow of fibers and fragments is $1.07 \times 10^{6}$ fibers/person/year and $0.42 \times 10^{6}$ fragments/person/year, respectively. Upstream of urban Neiva, the watershed area of the Magdalena River is $32,800 \mathrm{~km}^{2}$ [93] with a population density of 5.9 people $/ \mathrm{km}^{2}$ [94], giving an estimated population of 193,600 people. With measured values of 0.097 fibers $/ \mathrm{L}$ and 0.0133 fragments/L at Site 1 , this calculates to an annual per capita outflow of $4.74 \times 10^{6}$ fibers/person/year and $0.65 \times 10^{6}$ fragments/person/year. Although these values suggest a four- to five-fold increase in fiber outflow per person in the upstream agricultural region, it is difficult to determine based upon one sample if this difference is meaningful without a more comprehensive spatial and temporal sampling effort. Regardless of this difference, these values do illustrate that there is minimal difference (i.e., not an order of magnitude difference) in the annual production of fibers and fragments per capita whether from the agricultural upstream region or from the urban area. This finding supports our hypothesis that the microplastic particles observed in the Magdalena River water and sediments are mostly produced by consumer and household activities without much, if any, industrial or manufacturing input.

Twenty one detailed studies of microplastic particles in river water and sediments $[17-36,95,96]$ present microplastic particle concentrations in the surface water ranging from $10^{-1}$ to $10^{2}$ particles/L with no apparent correlation to population density, geographical location, or land use. However, in all but one study [21], fibers constituted $50-90 \%$ of the total microplastic particles. Moreover, in the six studies $[21,22,26,30,31,62]$ that characterized the microplastic particle composition, five found that $50 \%$ or more of the particles were comprised of PE or PP, with PET, PS, and Nylon making up the remainder. Only one study detected polyester fibers [26] and another identified acrylic, rayon, and polyester fibers [96]. These findings, along with those from the Magdalena River, indicate that fibers are the most prevalent microplastic particles present in global river waters and sediments. Moreover, these fibers are not from synthetic woven textiles but rather appear to originate from degradation of nonwoven synthetic textiles. However, addressing this hypothesis will require more detailed analyses of microplastic fibers polymeric composition and width. Whether PE and PP microfibers are not adequately removed by wastewater treatment processes or if other transport mechanisms exist, such as atmospheric transport $[95,97]$, needs to be explored in more detail.

\section{Conclusions}

The origin, transport and fate of microplastic particles in rivers is a complex, dynamic process that is determined by land use, waste disposal methods, population density, surface hydrology, climate, and geography. Due to the absence of an industrial and manufacturing sector in the city of Neiva, this study utilized Neiva to characterize the contribution of raw wastewater outflow and household activities in a midsized urban environment on the amount and type of microplastic particles deposited into the river water and sediments. Approximately $15 \%$ of the total microplastic particle input from Neiva into the Magdalena River is due to fragments comprised of PP, PE, and PET from upstream agricultural practices as well as presumably the degradation of PET-based drinking water bottles and consumer packaging. The remaining $84 \%$ input is from PE, PP, PS, and nylon microplastic fibers. The observation of fiber widths of $<20 \mu \mathrm{m}$ in this study, along with the lack of acrylic and polyester fibers that are used predominantly in woven synthetic textiles, indicated that the degradation of nonwoven synthetic textiles is the dominant origin of these microplastic fibers. This study is the first the authors know of that clearly indicates the impact of microplastic fibers originating from nonwoven synthetic textiles. Without detailed analysis of the polymeric composition of the microplastic fibers, as well as the extensive measurement of fiber widths, this conclusion would not be possible. This is an important finding because microplastic fibers are often assumed to originate from the washing of woven synthetic textiles. Therefore, it is our recommendation that studies of microplastic fibers take special consideration of polymer composition and morphology to ensure accurate characterization and identification of their origin. 
Author Contributions: Conceptualization, P.M.S. and M.A.N.; methodology, P.M.S.; software, P.M.S.; formal analysis, P.M.S. and M.A.N.; investigation, P.M.S.; writing-original draft preparation, review and editing, P.M.S. and M.A.N. All authors have read and agreed to the published version of the manuscript.

Funding: P.M.S. was funded with a Faculty Research Travel Scholarship by Corhuila University to visit the University of Oklahoma to conduct Raman microscope and SEM analyses.

Acknowledgments: Alejandra Hernandez's assistance with preparing samples and collecting SEM images is greatly appreciated.

Conflicts of Interest: The authors declare no conflict of interest. The funders had no role in the design of the study; in the collection, analyses, or interpretation of data; in the writing of the manuscript, or in the decision to publish the results.

\section{References}

1. Barnes, D.K.; Galgani, F.; Thompson, R.C.; Barlaz, M. Accumulation and fragmentation of plastic debris in global environments. Philos. Trans. R. Soc. 2009, 364, 1985-1998. [CrossRef] [PubMed]

2. Browne, M.A.; Crump, P.; Niven, S.J.; Teuten, E.L.; Tonkin, A.; Gallowa, T.; Thompson, R.C. Accumulations of microplastic on shorelines worldwide: Sources and sinks. Environ. Sci. Technol. 2011, 45, 9175-9179. [CrossRef] [PubMed]

3. Koelmans, A.A.; Besseling, E.; Shim, W.J. Nanoplastics in the Aquatic Environment. Critical Review. In Marine Anthropogenic Litter; Bergmann, M., Gutow, L., Klages, M., Eds.; Springer: Cham, Switzerland, 2015; pp. 325-340.

4. Lambert, S.; Wagner, M. Characterisation of nanoplastics during the degradation of polystyrene. Chemosphere 2016, 145, 265-268. [CrossRef]

5. $\quad$ Eriksen, M.; Mason, S.; Wilson, S.; Box, C.; Zellers, A.; Edwards, W.; Farley, H.; Amato, S. Microplastic pollution in the surface waters of the Laurentian Great Lakes. Mar. Pollut. Bull. 2013, 77, 177-182. [CrossRef] [PubMed]

6. Galgani, F.; Hanke, G.; Maes, T. Global distribution, composition and abundance of marine litter. In Marine Anthropogenic Litter; Bergmann, M., Gutow, L., Klages, M., Eds.; Springer International Publishing: Basel, Switzerland, 2015; pp. 29-56.

7. Barrows, A.P.W.; Cathey, S.E.; Petersen, C.W. Marine environment microfiber contamination: Global patterns and the diversity of microparticle origins. Environ. Pollut. 2018, 237, 275-284. [CrossRef] [PubMed]

8. Rios, L.M.; Mendoza, A.C.; Patrick, R.J. Characterization of microplastics and toxic chemicals extracted from microplastic samples from the North Pacific Gyre. Environ. Chem. 2015. [CrossRef]

9. Wang, W.; Wang, J. Investigation of microplastics in aquatic environments: An overview of the methods used, from field sampling to laboratory analysis. Trends Anal. Chem. 2018, 108, 195-202. [CrossRef]

10. Thompson, R.C.; Olsen, Y.; Mitchell, R.P.; Davis, A.; Rowland, S.J.; John, A.W.G.; McGonigle, D.; Russell, A.E. Lost at sea: Where is all the plastic? Science 2004, 304, 838. [CrossRef]

11. Arthur, C.; Baker, J. Proceedings of the Second Research Workshop on Microplastic Debris, NOAA Technical Memorandum NOS-OR\&R-39. Tacoma, WA, USA, 5-6 November 2010.

12. Lusher, A.L.; Tirelli, V.; O'Connor, I.; Officer, R. Microplastics in Arctic polar waters: The first reported values of particles in surface and sub-surface samples. Sci. Rep. 2015, 5, 14947. [CrossRef]

13. Sadri, S.S.; Thompson, R.C. On the quantity and composition of floating plastic debris entering and leaving the Tamar estuary, Southwest England. Mar. Pollut. Bull. 2014, 81, 55-60. [CrossRef]

14. Wagner, M.; Scherer, C.; Alvarez-Muñoz, D.; Brennholt, N.; Bourrain, X.; Buchinger, S.; Fries, E.; Grosbois, C.; Klasmeier, J.; Marti, T.; et al. Microplastics in freshwater ecosystems: What we know and what we need to know. Environ. Sci. Eur. 2014, 26, 12. [CrossRef] [PubMed]

15. Zbyszewski, M.; Corcoran, P.L.; Hockin, A. Comparison of the distribution and degradation of plastic debris along shorelines of the Great Lakes, North America. J. Great Lakes Res. 2014, 40, 288-299. [CrossRef]

16. Zhang, L.; Liu, J.; Xie, Y.; Zhong, S.; Yang, B.; Lu, D.; Zhong, Q. Distribution of microplastics in surface water and sediments of Qin River in Beibu Gulf, China. Sci. Total Environ. 2020, 708, 135176. [CrossRef] [PubMed]

17. Grbic, J.; Helm, P.; Athey, S.; Rochman, C.M. Microplastics entering northwestern Lake Ontario are diverse and linked to urban sources. Water Res. 2020, 174, 115623. [CrossRef] 
18. Alam, F.C.; Sembiring, E.; Setiani Muntalif, B.; Suendo, V. Microplastic distribution in surface water and sediment river around slum and industrial area (case study: Ciwalengke River, Majalaya district, Indonesia). Chemosphere 2019, 224, 637-645. [CrossRef]

19. Kataoka, T.; Nihei, Y.; Kudou, K.; Hinata, H. Assessment of the sources and inflow processes of microplastics in the river environments of Japan. Environ. Pollut. 2019, 244, 958-965. [CrossRef]

20. Shruti, V.C.; Jonathan, M.P.; Rodriguez-Espinosa, P.F.; Rodriguez-Gonzalez, F. Microplastics in freshwater sediments of Atoyac River basin, Puebla City, Mexico. Sci. Total Environ. 2019, 654, 154-163. [CrossRef] [PubMed]

21. Fan, Y.; Zheng, K.; Zhu, Z.; Chen, G.Y.; Peng, X. Distribution, sedimentary record, and persistence of microplastics in the Pearl River catchment, China. Environ. Pollut. 2019, 251, 862-870. [CrossRef]

22. Jiang, J.; Yin, L.; Zhiwei, L.; Wen, X.; Luo, X.; Hu, S.; Yang, H.; Long, Y.; Deng, B.; Huang, L.; et al. Microplastic pollution in the rivers of the Tibet Plateau. Environ. Pollut. 2019, 249, 91-98. [CrossRef]

23. Fahrenfeld, N.L.; Arbuckle-Keil, G.; Naderi Beni, N. Source tracking microplastics in the freshwater environment. Trends Anal. Chem. 2019, 112, 248-254. [CrossRef]

24. Wagner, S.; Klockner, P.; Stier, B.; Romer, M.; Seiwert, B.; Reentsma, T.; Schmidt, C. Relationship between Discharge and River Plastic Concentrations in a Rural and an Urban Catchment. Environ. Sci. Technol. 2019, 53, 10082-10091. [CrossRef] [PubMed]

25. Watkins, L.; Sullivan, P.J.; Walter, T.M. A case study investigating temporal factors that influence microplastic concentration in streams under different treatment regimes. Environ. Sci. Pollut. Res. 2019, 26, 21797-21807. [CrossRef] [PubMed]

26. Kapp, K.J.; Yeatman, E. Microplastic hotspots in the Snake and Lower Columbia rivers: A journey from the Greater Yellowstone Ecosystem to the Pacific Ocean. Environ. Pollut. 2018, 241, 1082-1090. [CrossRef] [PubMed]

27. Nel, H.A.; Dalu, T.; Wasserman, R.J. Sinks and sources: Assessing microplastic abundance in river sediment and deposit feeders in an Austral temperate urban river system. Sci. Total Environ. 2018, 612, 9500-9956. [CrossRef] [PubMed]

28. Tibbetts, J.; Krause, S.; Lynch, I.; Smith, S.; Gregory, H. Abundance, Distribution, and Drivers of Microplastic Contamination in Urban River Environments. Water 2018, 10, 1597. [CrossRef]

29. Xiong, X.; Zhang, K.; Chen, X.; Shi, H.; Luo, Z.; Wu, C. Sources and distribution of microplastics in China's largest inland lake-Qinghai Lake. Environ. Pollut. 2018, 235, 899-906. [CrossRef]

30. Di, M.; Wang, J. Microplastics in surface waters and sediments of the Three Gorges Reservoir, China. Sci. Total Environ 2018, 616-617, 1620-1627. [CrossRef]

31. Barrows Abigail, P.W.; Christiansen, K.S.; Bode, E.T.; Hoellein, T.J. A watershed-scale, citizen approach to quantifying microplastic concentration in a mixed land-use river. Water Res. 2018, 147, 382-392. [CrossRef]

32. Dris, R.; Gasperi, J.; Rocher, V.; Tassin, B. Synthetic and non-synthetic anthropogenic fibers in a river under the impact of Paris Megacity: Sampling methodological aspects and flux estimations. Sci. Total Environ. 2018, 618, 157-164. [CrossRef]

33. Leslie, H.A.; Brandsma, S.H.; van Velzen, M.J.M.; Vethaak, A.D. Microplastics en route: Field measurements in the Dutch river delta and Amsterdam canals, wastewater treatment plants, North Sea sediments and biota. Environ. Int. 2017, 101, 133-142. [CrossRef]

34. Miller, R.Z.; Watts Andrew, J.R.; Winslow, B.O.; Galloway, T.S.; Barrows, A.P.W. Mountains to the sea: River study of plastic and non-plastic microfiber pollution in the northeast USA. Mar. Pollut. Bull. 2017, 124, 245-251. [CrossRef]

35. Klein, S.; Worch, E.; Knepper, T.P. Occurrence and Spatial Distribution of Microplastics in River Shore Sediments of the Rhine-Main Area in Germany. Environ. Sci. Technol. 2015, 49, 6070-6076. [CrossRef] [PubMed]

36. Zhao, S.; Zhu, L.; Wang, T.; Li, D. Suspended microplastics in the surface water of the Yangtze Estuary System, China: First observations on occurrence, distribution. Mar. Pollut. Bull. 2014, 86, 562-568. [CrossRef] [PubMed]

37. Crawford, C.; Quinn, B. 8-Microplastic Collection Techniques. In Microplastic Pollutants; Elsevier: Amsterdam, the Netherlands, 2017; pp. 179-202.

38. Crawford, C.B.; Quinn, B. 10-Microplastic Identification Techniques. In Microplastic Pollutants; Elsevier: Amsterdam, the Netherlands, 2017; pp. 219-267. 
39. Crawford, C.B.; Quinn, B. 9-Microplastic Separation Techniques. In Microplastic Pollutants; Elsevier: Amsterdam, the Netherlands, 2017; pp. 203-218.

40. Silva, A.B.; Bastos, A.S.; Justino, C.I.L.; da Costa, J.P.; Duarte, A.C.; Rocha, S.A. Microplastics in the environment: Challenges in analytical chemistry: A review. Anal. Chim. Acta 2018, 1017, 1-19. [CrossRef] [PubMed]

41. Cincinelli, A.; Scopetani, C.; Chelazzi, D.; Lombardini, E.; Martellini, T.; Katsoyiannis, A.; Fossi, M.C.; Corsolini, S. Microplastic in the surface waters of the Ross Sea (Antarctica): Occurrence, distribution and characterization by FTIR. Chemosphere 2017, 175, 391-400. [CrossRef] [PubMed]

42. Woodall, L.C.; Sanchez-Vidal, A.; Thompson, R.C. The deep sea is a major sink for microplastic debris. R. Soc. Open Sci. 2014, 1, 140317. [CrossRef] [PubMed]

43. Zobkov, M.B.; Esiukova, E.E. Microplastics in a marine environment: Review of methods for sampling, processing, and analyzing microplastics in water, bottom sediments, and coastal deposits. Oceanology 2018, 58, 137-143. [CrossRef]

44. Hanvey, J.S.; Lewis, P.J.; Lavers, J.L.; Crosbie, N.D.; Pozo, K.; Clarke, B.O. A review of analytical techniques for quantifying microplastics in sediments. Anal. Methods 2017, 9, 1369-1383. [CrossRef]

45. Nuelle, M.-T.; Dekiff, J.H.; Remy, D.; Fries, E. A new analytical approach for monitoring microplastics in marine sediments. Environ. Pollut. 2014, 184, 161-169. [CrossRef]

46. Wang, W.; Ndungu, A.W.; Li, Z.; Wang, J. Microplastics pollution in inland freshwaters of China: A case study in urban surface waters of Wuhan, China. Sci. Total Environ. 2017, 575, 1369-1374. [CrossRef]

47. Su, L.; Cai, H.; Kolandhasamy, P.; Wu, C.; Rochman, C.M.; Shi, H. Using the Asian clam as an indicator of microplastic pollution in freshwater ecosystems. Environ. Pollut. 2018, 234, 347-355. [CrossRef]

48. Lorenzo-Navarro, J.; Castrillón-Santana, M.; Gómez, M.; Herrera, A.; Marín-Reyes, P. Automatic Counting and Classification of Microplastic Particles. In Proceedings of the 7th International Conference on Pattern Recognition Applications and Methods, ICPRAM 2018, Madeira, Portugal, 16-18 January 2018; pp. 646-652, ISBN 978-989-758-276-9.

49. Zhong, P.; Huige, H.; Hongzhe, C.; Sumin, W.; Xiuwu, S.; Qingping, Z.; Yuanbiao, Z.; Hui, L.; Shangzhan, C.; Jiang, H. Microplastics in the Northwestern Pacific: Abundance, distribution, and characteristics. Sci. Total Environ. 2019, 650, 1913-1922. [CrossRef]

50. Schymansky, D.; Goldbeck, C.; Humpf, H.U.; Fürst, P. Analysis of microplastics in water by micro-Raman spectroscopy: Release of plastic particles from different packaging into mineral water. Water Res. 2018, 129, 154-162. [CrossRef] [PubMed]

51. Oßmann, B.E.; Sarau, G.; Holtmannspötter, H.; Pischetsrieder, M.; Christiansen, S.H.; Dicke, W. Small-sized microplastics and pigmented particles in bottled mineral water. Water Res. 2018, 141, 307-316. [CrossRef] [PubMed]

52. Lenz, R.; Enders, K.; Stedmon, K.; Mackenzie, D.; Nielsen, T. A critical assessment of visual identification of marinemicroplastic using Raman spectroscopy for analysis improvement. Mar. Pollut. Bull. 2015, 100, 82-91. [CrossRef]

53. Anger, P.; von der Esch, E.; Baumann, T.; Elsner, M.; Niessner, R.; Ivleva, N. Raman microspectroscopy as a tool for microplastic particle analysis. Trends Anal. Chem. 2018, 109, 214-226. [CrossRef]

54. Araujo, C.F.; Nolasco, M.M.; Ribeiro, A.M.P.; Ribeiro-Claro, P.J. Identification of microplastics using Raman spectroscopy: Latest developments and future prospects. Water Res. 2018, 142, 426-440. [CrossRef]

55. Zada, L.; Leslie, H.A.; Vethaak, A.D.; Tinnevelt, G.H.; Jansen, J.J.; de Boer, J.F.; Ariese, F. Fast Microplastics identification with stimulated Raman scattering microscopy. J. Raman Spectrosc. 2018, 49, 1136-1144. [CrossRef]

56. Xu, J.; Thomas, K.; Luo, Z.; Gowen, A. FTIR and Raman imaging for microplastics analysis: State of the art, challenges and prospects. Trends Anal. Chem. 2019, 119, 115629. [CrossRef]

57. Fortin, S.; Song, B.; Burbage, C. Quantifying and identifying microplastics in the effluent of advanced wastewater treatment systems using Raman microspectroscopy. Mar. Pollut. Bull. 2019, 149, 110579. [CrossRef]

58. Wolff, S.; Kerpen, J.; Prediger, J.; Barkmann, L.; Müller, L. A critical assessment of visual identification of marinemicroplastic using Raman spectroscopy for analysis improvement. Water Res. 2019, 2, 100014. [CrossRef] 
59. Image J-Open source Java image processing program. Available online: https://imagej.net/ (accessed on 15 January 2020).

60. Leads, R.; Weinstein, J. Occurrence of tire wear particles and other microplastics within the tributaries of the Charleston Harbor Estuary, South Carolina, USA. Mar. Pollut. Bull. 2019, 145, 569-582. [CrossRef] [PubMed]

61. Huila Government. Available online: https://www.huila.gov.co/publicaciones/5148/actividad-economicadel-departamento-17736/ (accessed on 1 December 2019).

62. Zhang, L.; Xie, Y.; Liu, J.; Zhong, S.; Qian, Y.; Gao, P. An Overlooked Entry Pathway of Microplastics into Agricultural Soils from Application of Sludge-Based Fertilizers. Environ. Sci. Technol. 2020. [CrossRef] [PubMed]

63. Ng, E.; Lwanga, E.H.; Eldridge, S.M.; Johnston, P.; Hu, H.; Geissen, V.; Chen, D. An overview of microplastic and nanoplastic pollution in agroecosystems. Sci. Total Environ. 2018, 627, 1377-1388. [CrossRef] [PubMed]

64. Huang, Y.; Liu, Q.; Jia, W.; Yan, C.; Wang, J. Agricultural plastic mulching as a source of microplastics in the terrestrial environment. Environ. Pollut. 2020, 260, 114096. [CrossRef] [PubMed]

65. Corradini, F.; Meza, P.; Eguiluz, R.; Casado, F.; Huerta-Lwanga, E.; Geissen, V. Evidence of microplastic accumulation in agricultural soils from sewage sludge disposal. Sci. Total Environ. 2019, 671, 411-420. [CrossRef] [PubMed]

66. Liu, M.; Lu, S.; Song, Y.; Lei, L.; Hu, J.; Lv, W.; Zhou, W.; Cao, C.; Shi, H.; Yang, X.; et al. Microplastic and mesoplastic pollution in farmland soils in suburbs of Shanghi, China. Environ. Pollut. 2018, 242, 855-862. [CrossRef]

67. Steinmetz, Z.; Wollman, C.; Schaefer, M.; Buchmann, C.; David, J.; Troger, J.; Munoz, K.; Fror, O.; Schaumann, G.E. Plastic mulching in agriculture. Trading short-term agronomic benefits for long-term soil degradation? Sci. Total Environ. 2016, 550, 690-705. [CrossRef]

68. Campanale, C.; Stock, F.; Massarelli, C.; Kochleus, C.; Bagnuolo, G.; Reifferscheid, G.; Felice Uricchio, V. Microplastics and their possible sources: The example of Ofanto river in southeast Italy. Environ. Pollut. 2020, 258, 113284. [CrossRef]

69. Piehl, S.; Leibner, A.; Loder, M.G.J.; Dris, R.; Bogner, C.; Laforsch, C. Identification and quantification of macro- and microplastics on an agricultural farmland. Sci. Rep. 2018, 8, 17950. [CrossRef]

70. Edo, C.; Gonzalez-Pleiter, M.; Leganes, F.; Fernandez-Pinas, F.; Rosal, R. Fate of microplastics in wastewater treatment plants and their environmental dispersion with effluent and sludge. Environ. Pollut. 2020, 259, 113837. [CrossRef]

71. Park, H.; Oh, M.; Kim, P.; Kim, G.; Jeong, D.; Ju, B.; Lee, W.; Chung, H.; Kang, H.; Kwon, J. National Reconnaissance Survey of Microplastics in Municipal Wastewater Treatment Plants in Korea. Environ. Sci. Technol. 2020, 54, 1503-1512. [CrossRef] [PubMed]

72. Blair, R.M.; Waldron, S.; Gauchotte-Lindsay, C. Average daily flow of microplastics through a tertiary wastewater treatment plant over a ten-month period. Water Res. 2019, 163, 114909. [CrossRef] [PubMed]

73. Conley, K.; Clum, A.; Deepe, J.; Lane, H.; Beckingham, B. Wastewater treatment plants as a source of microplastics to an urban estuary: Removal efficiencies and loading per capita over one year. Water Res. 2019, 3, 100030. [CrossRef] [PubMed]

74. Gatidou, G.; Arvaniti, O.S.; Stasinakis, A.S. Review on the occurrence and fate of microplastics in Sewage Treatment Plants. J. Hazard. Mater. 2019, 367, 504-512. [CrossRef]

75. Yang, L.; Li, K.; Cui, S.; Kang, Y.; Lihui, L. Removal of microplastics in municipal sewage from China's largest water reclamation plant. Water Res. 2019, 155, 175-181. [CrossRef]

76. Akarsu, C.; Kumbur, H.; Gokdag, K.; Kideys, A.E.; Sanchez-Vidal, A. Microplastics composition and load from three wastewater treatment plants discharging into Mersin Bay, north eastern Mediterranean Sea. Mar. Poll. Bull. 2020, 150, 110776. [CrossRef]

77. Cesa, F.S.; Turra, A.; Herminio Checon, H.; Leonardi, B.; Baruque-Ramos, J. Laundering and textile parameters influence fibers release in household washings. Environ. Pollut. 2020, 257, 113553. [CrossRef]

78. Cesa, F.S.; Turra, A.; Baruque-Ramos, J. Synthetic fibers as microplastics in the marine environment: A review from textile perspective with a focus on domestic washings. Sci. Total Environ. 2017, 598, 1116-1129. [CrossRef]

79. Hartline Niko, L.; Bruce, N.J.; Karba, S.N.; Ruff, E.O.; Sonar, S.U.; Holden, P.A. Microfiber Masses Recovered from Conventional Machine Washing of New or Aged Garments. Environ. Sci. Technol. 2016, 11532-11538. [CrossRef] 
80. Pirc, U.; Vidmar, M.; Mozer, A.; Krzan, A. Emissions of microplastic fibers from microfiber fleece during domestic washing. Environ. Sci. Pollut. Res. 2016, 23, 22206-22211. [CrossRef]

81. Sieber, R.; Kawecki, D.; Nowack, B. Dynamic probabilistic material flow analysis of rubber release from tires into the environment. Environ. Pollut. 2020, 258, 113573. [CrossRef] [PubMed]

82. Ziajahromi, S.; Drapper, D.; Hornbuckle ARintoul, L.; Leusch, F. Microplastic pollution in a stormwater floating treatment wetland: Detection of tyre particles in sediment. Sci. Total Environ. 2020, 13, 136356. [CrossRef] [PubMed]

83. Goodfellow Cambridge Ltd. Huntingdon, England PE29 6WR. Available online: http://www.goodfellow.com (accessed on 15 January 2020).

84. MiniFibers, Inc. Available online: https://www.minifibers.com/applications/specialty-papers-nonwovens/ (accessed on 15 January 2020).

85. Deopura, B.L.; Padaki, N.V. Synthetic Textile Fibres: Polyamide, Polyester and Aramid Fibres, 97-114. In Textiles and Fashion: Materials, Design and Technology; Woodhead Publishing Series in Textiles; Sinclair, R., Ed.; Woodhead Publishing: Cambridge, UK, 2017. [CrossRef]

86. Stratistics Market Research Consulting Pvt. Ltd. Nonwoven Fabrics-Global Market. Outlook (2017-2026); Analytical Research Cognizance: New York, NY, USA, 2018; ID: 90384.

87. Kellie, G. Introduction to Technical Nonwovens, in Advances in Technical Nonwovens; Elsevier Ltd.: Amsterdam, the Netherlands, 2016. [CrossRef]

88. Yesil, Y.; Bhat, G.S. Structure and mechanical properties of polyethylene melt blown nonwovens. Int. J. Cloth. Sci. Technol. 2016, 28, 780-793. [CrossRef]

89. Sinclair, R. Understanding Textile Fibres and Their Properties: What is a Textile Fibre? 3-27. In Textiles and Fashion: Materials, Design and Technology; Woodhead Publishing Series in Textiles; Sinclair, R., Ed.; Woodhead Publishing: Cambridge, UK, 2015. [CrossRef]

90. Mao, N.; Russell, S.J. Fiber to Fabric: Nonwoven Fabrics, 307-335. In Textiles and Fashion: Materials, Design and Technology; Woodhead Publishing Series in Textiles; Sinclair, R., Ed.; Woodhead Publishing: Cambridge, UK, 2015. [CrossRef]

91. City Population, Thomas Brinkhoff, Oldenburg, Germany. Available online: http://www.citypopulation.de/ en/colombia/cities/ (accessed on 15 January 2020).

92. Galvis, G.Y.; Mojica, I. The Magdalena River fresh water fishes and fisheries. Aquat. Ecosyst. Health Manag. 2007, 10, 127-139. [CrossRef]

93. International Rivers. Available online: www.internationalrivers.org/resources/9195 (accessed on 28 February 2020).

94. Population.City. Available online: http://population.city/colombia/neiva/ (accessed on 28 February 2020).

95. Zhang, Y.; Kang, S.; Allen, S.; Allen, D.; Gao, T.; Sillanpaa, M. Atmospheric microplastics: A review on current status and perspectives. Earth-Sci. Rev. 2020, 203, 103118. [CrossRef]

96. Peller, J.R.; Eberhardt, L.; Clark, R.; Nelson, C.; Kostelnik, E.; Iceman, C. Tracking the distribution of microfiber pollution in a southern Lake Michigan watershed through the analysis of water, sediment and air. Environ. Sci. Process. Impacts 2019, 21, 1549-1559. [CrossRef]

97. Chen, G.; Feng, Q.; Wang, J. Mini-review of microplastics in the atmosphere and their risks to humans. Sci. Total Environ. 2020, 703, 135504. [CrossRef]

(C) 2020 by the authors. Licensee MDPI, Basel, Switzerland. This article is an open access article distributed under the terms and conditions of the Creative Commons Attribution (CC BY) license (http://creativecommons.org/licenses/by/4.0/). 